\title{
Revamping Fashion E-Commerce in India using Artificial Intelligence
}

\author{
Anagha Chacko A, Santhvana Wilson and Shakeel Iqbal* \\ Department of Fashion Technology, National Institute of Fashion Technology, Hyderabad India
}

Submission: August 07, 2020; Published: August 31, 2020

*Corresponding author: Shakeel Iqbal, Department of Fashion Technology, National Institute of Fashion Technology, Madhapur, Opposite Cyber Tower, Hyderabad, India

\begin{abstract}
The research is about methods and lucrative ideas to remodel the various fashion E-commerce platforms with the help of Artificial Intelligence. The advent of technology in E-commerce has brought the concept of Artificial Intelligence upfront. It is subsequently notable that in India, introduction, and usage of AI tools in fashion E-commerce is very limited and people are not aware of the perks of the same. The problem that was associated to the research was the general awareness about the AI tools used in E-commerce applications. But beside that, people had several other problems that dealt with customer satisfaction levels. We conducted a survey and the responses collected were used to study the general patterns of concerns of the customers or the users. The assumptions were made concrete after analysis solely based on the findings. The secondary research added to helping tackle these issues faced by the customers in the most efficient manner possible. Hence extending the potential of Artificial intelligence in the field of E-commerce for Fashion sector.
\end{abstract}

Keywords: Artificial Intelligence; Fashion trend forecasting; Virtual reality; Augmented reality; Apparel E-commerce; Chatbots; Image searching; Voice recognition

\section{Introduction}

Fashion E-commerce is booming with its ease of selling goods and services to people across the world. With the advent of technology, E-commerce has expanded radically and significantly. The concept of E-commerce applied to the fashion industry is not novel anymore. People are looking for novelty factor with every sale. With E-commerce, fashion products are easier to discover, surf and purchase at greater deals. This even leads to the potential of Brick and mortar stores losing their value after all. Shattering the geographical barriers, the virtual world creates a provision for buyers and sellers to interact and do business. Customers can shop whenever they want from wherever they are at. The rapidly growing competition in Apparel E-commerce has led to competitors looking out for something that would give their services a cutting edge.

This is where Artificial Intelligence should be introduced. Artificial intelligence (AI) is that aspect of computer enhancement where a machine can adapt itself and learn and build upon itself from simulations that get enforced around it. The machine behaves and responds like a human, eliminating any degree of doubt of inhuman behaviourism. The ability to reach the closest possible to human thinking makes interactions between man and machine easier and much more efficient. This quality of a machine being able to produce human characteristics is called Artificial Intelligence. There are many types of AI: Analytic AI (sentiment analysis, supplier risk assessment), Functional AI (interactive solutions, robots), Interactive AI (chatbots, personal assistants), Text AI (text recognition, speech-to-text conversion) and Visual AI (computer vision, augmented reality. With the recent developments that have been surfacing around Artificial Intelligence and their creative and efficient application in E-commerce and in the Industry in itself, the research aims to provide an approach to remodel the use of AI to solve and improve customer satisfaction and target the problems that the customer might be facing and give feasible solutions with the help of AI. AI is also capable of plowing the fake reviews providing for an authentic customer experience.

\section{Objective}

i. We aim to find the scope of improvement and the problems faced by a customer while shopping online.

ii. The intention is to spread awareness to the average customer about an AI powered site that in other circumstances he or she might probably not be aware of.

iii. We aim to provide feasible solutions keeping the target audience and each of their problems in mind. 
iv. To review the discrepancies, the customers might face, they can be clubbed into categories and find precise solutions on an individual basis making no room for any ambiguity.

v. To introduce AI to the country and potential enhancements would be capable to identify data, collect data, classify data and the take smart decisions based on simple inputs.

\section{Literature Review}

Few recent studies have focused on various Artificial Intelligence (AI) techniques that are used in the design and development of various E-commerce websites [1]. But there are no review papers available on how to improve user interface and customer satisfaction in E-commerce websites using AI. Sales of apparel and E-commerce retailers are projected to top $\$ 170$ billion by 2022 [2]. This shows the importance of improving the existing E-commerce websites. So, there is a need to study whether the customers are satisfied with the existing services offered by the E-commerce websites and if not, then improve them, to maximize their shopping experience from E-commerce sites. Fashion companies that effectively utilize the suitable technologies would be able to increase their competitive advantage towards customizing products and shopping experiences, filtering logistical process that nibbles away at budgets [3]. This shows the need of AI to be integrated with the E-Commerce websites to improve the shopping experience of the customers.

The Apparel E-commerce sector still lacks the extensive adoption of AI methods. The apparel E-commerce sector is still using computational tools based on classical algorithms and modern AI techniques are confined to academic research. Hence, it is a requisite for the sector to adopt new $\mathrm{AI}$ techniques to have a competitive advantage and improve business profitability [4]. AI has empowered the users with the many high-tech experiences ranging from stores to websites and from chatbots to voice assistants. Such evolution has made the consumers approach the brand services any time from any form. AI right from the starting disrupted the entire apparel E-commerce industry with smart solutions [5]. In E-commerce websites, AI can be used primarily for product selection and recommendation, negotiation, auctions, solving real-world scheduling problems and enhancing servers' scalability, generating automated responses, and decisions on bundling and pricing of goods, etc. [ 1,6,7].

Many E-commerce websites use AI. Amazon's Alexa, Beijingbased JD.com partnered up with Siasun Robot \& Automation Co Ltd., Tmall Genie and Ali Assistant of Alibaba, eBay Shopbot, voice recognition systems in ASOS and Rakuten are some of them. AI is on the rise in the apparel E-commerce industry; however, it is still far from being perfect. It is believed that Artificial Intelligence in apparel E-commerce will impact transactions, customer retention, satisfaction, efficiency and many more. AI is changing the way we buy and sell online [8-10]. Though AI can be used in these many areas during user interface, not all the apparel E-commerce websites in India uses it. Even though Indian Fashion E-Commerce websites like Myntra uses AI technology not just in helping the design and marketing team cut down design time from six months to just one and helps to give the customer accurate prediction as per what's trending, it also provides AI tools like smart cam and voice recognition facility for the customers to assist in searching. E-commerce websites like Amazon and Flipkart also uses various AI techniques to improve their customer's shopping experience [11]. Flipkart's AI project known as 'Mira' aims to deliver an offline experience to online shopping. Amazon also uses AI in correcting address improving catalog quality, products size recommendations, improving product search etc [12].

\section{Research Methodology}

An online survey was conducted using Google forms distributed amidst the people via platforms like Gmail and WhatsApp. 334 samples were collected, and their responses have been deciphered and analyzed. The demographic variables were age and gender and the dependent variables were preference for buying, factors influencing the users as customers, awareness, and interactivity with existing AI tools, etc. The questionnaire consisted of about 14 questions and the feedback was concise and telling in terms of what actions could be taken to improve the customer satisfaction. We received responses from 206 females and 128 males [13]. The age group from where we received most of our responses were from 20-35 years.

\section{Data Analysis \& Interpretation}

From the questionnaire circulated online through Google forms, responses of 334 people were collected who belonged to different categories of age groups. However, $74.6 \%$ of the sample size belonged to people in the category of 20-35 years of age (Figure 1). Size of the female population who answered the questionnaire $(61.7 \%)$ were more than the male population (38.3\%) (Figure 2) [14].

The survey asked the respondents to fill up how often they prefer shopping via E-commerce platforms to purchase apparel. From the survey results, it was observed that $32.6 \%$ often use E-commerce platforms to purchase apparel (Figure 3). The purpose of the question was to identify the comfort level that people have while interacting on an online platform. The survey also had a question which gave insight into identifying the apps on which users have experienced an interaction with AI. However, some of the people have even answered that they have experienced AI in websites like Tata Cliq and Jabong. This shows the unawareness amidst our respondents regarding the concept of AI. But the website that people did most often interact with AI was Amazon. $70 \%$ of the respondents experienced $\mathrm{AI}$ on Amazon followed by $60.8 \%$ for Flipkart and the least was $5.4 \%$ on Tata Cliq (Figure 4) [15]. 


\section{Current Trends in Fashion Technology \& Textile Engineering}

Figure 1: Age Groups
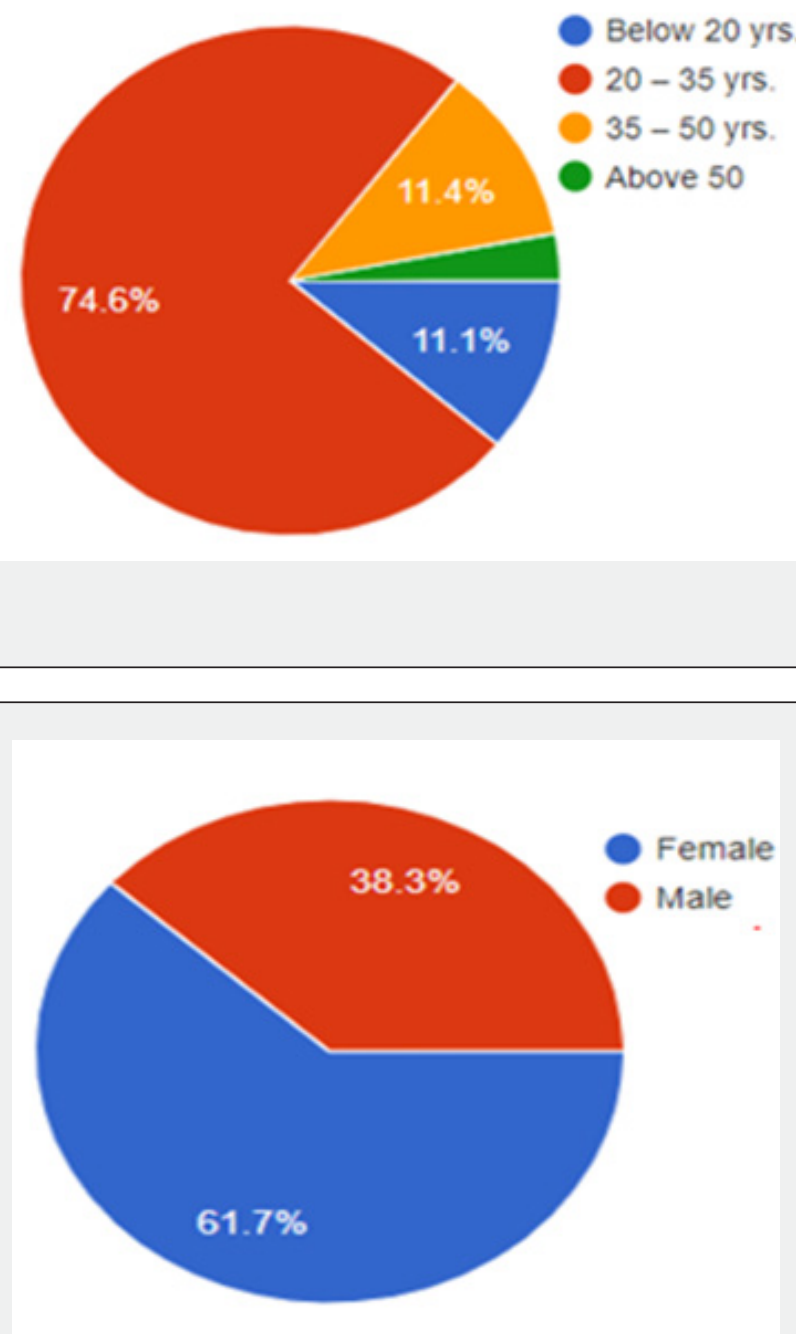

Figure 2: Gender.

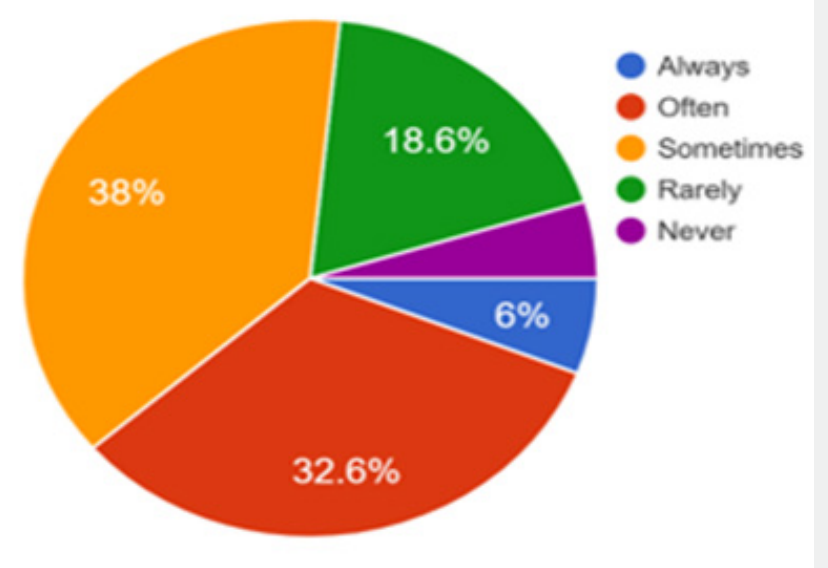

Figure 3: Frequency of using E-Commerce platform. 


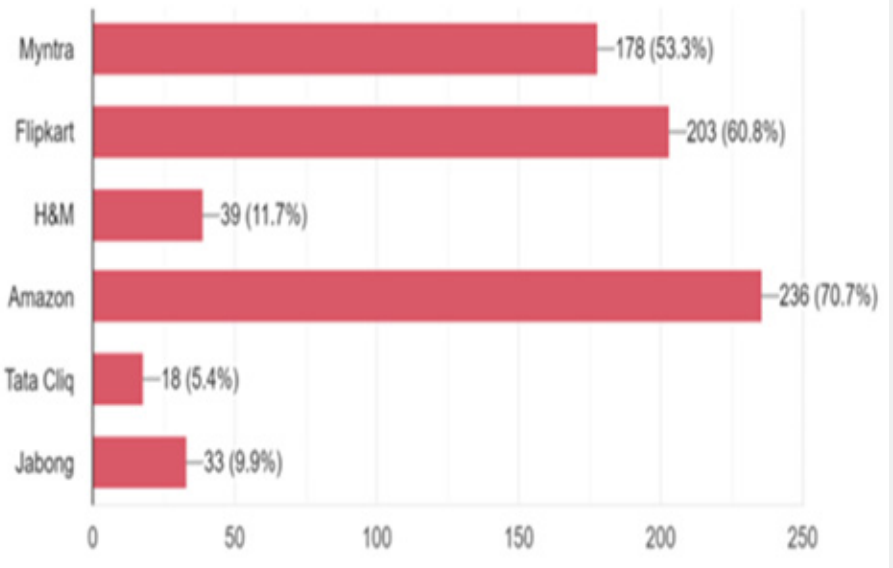

Figure 4: Websites on which people have experienced Al.

Table 1: One Variable Chi-Square test

\begin{tabular}{|c|c|c|c|}
\hline E- Commerce Website & Observed & Expected & (O-E)2/E \\
\hline Myntra & 178 & 55.5 & 270.3829 \\
\hline Flipkart & 203 & 55.5 & 392.0045 \\
\hline H\&M & 39 & 55.5 & 4.905405 \\
\hline Amazon & 235 & 55.5 & 580.545 \\
\hline Tata Cliq & 18 & 55.5 & 25.33784 \\
\hline Jabong & 33 & 55.5 & 9.121622 \\
\hline Chisquare & & 1282.297 & \\
\hline $\mathrm{df}=(\mathrm{C}-1)(\mathrm{R}-1)$ & & 11.07 & \\
\hline Critical value for chisq. & &
\end{tabular}

One-Variable Chi-Square test with equal expected frequencies was conducted to check whether people have experienced AI in all the websites equally or not (Table 1). For that, null hypothesis was stated as customers have experienced AI in all the E-Commerce websites and alternate hypothesis as customers have not experienced AI in all the E-Commerce websites, only in some of them. From the test, it was found that the calculated value of chi-square (1282.297) is greater than 11.07, thereby rejecting the null hypothesis that customers have experienced $\mathrm{AI}$ in all of the E-Commerce websites and hence accepting the alternative hypothesis that customers have not experienced AI in all the E-Commerce websites. The test helped to conclude that there is a significant difference among the frequencies with which customers have experienced AI interaction in different websites.

Based on the features of Live Chat, Customer feedback and Inquiries handling for Returns and or Exchange, the responses analyzed concluded that people have had several issues regarding inquiries for Returns and Exchange. The customers were also asked to express their degree of satisfaction with Live Chats offered by few platforms. A t-test was conducted which thus concluded that mean satisfaction level of customers on live chat is less than or equal to 3 , implying that the customers are very much dissatisfied with the existing live chat services offered by the E-Commerce websites. The survey asked the respondents whether they have ever observed pop up icons or predictive links based on their previous purchases. This was posed to understand the observation and awareness amidst online shoppers. From the results, $72.5 \%$ of them have come across predictive suggestion links and pop up icons, whereas $7.7 \%$ have not at all observed this (Figure 5).

The respondents were also asked to pick the particular aspect of AI that lead to predictive suggestions. This was done in order to know about the familiarity amidst customers about the terms and terminologies of AI.

$58 \%$ of people opted for All of the above while the correct answer was Neural Networking which was only opted by $11.3 \%$ of people (Figure 6). Respondents were also asked whether they have been ever influenced by these predictive suggestions offered online to which $55.4 \%$ responded Yes and $44.6 \%$ opted No (Figure 7) The purpose of the question was to understand the customer behaviour and psychology that leads to purchasing a product online using the help of AI. 
Figure 5: Response to Observation of Predictive Links.
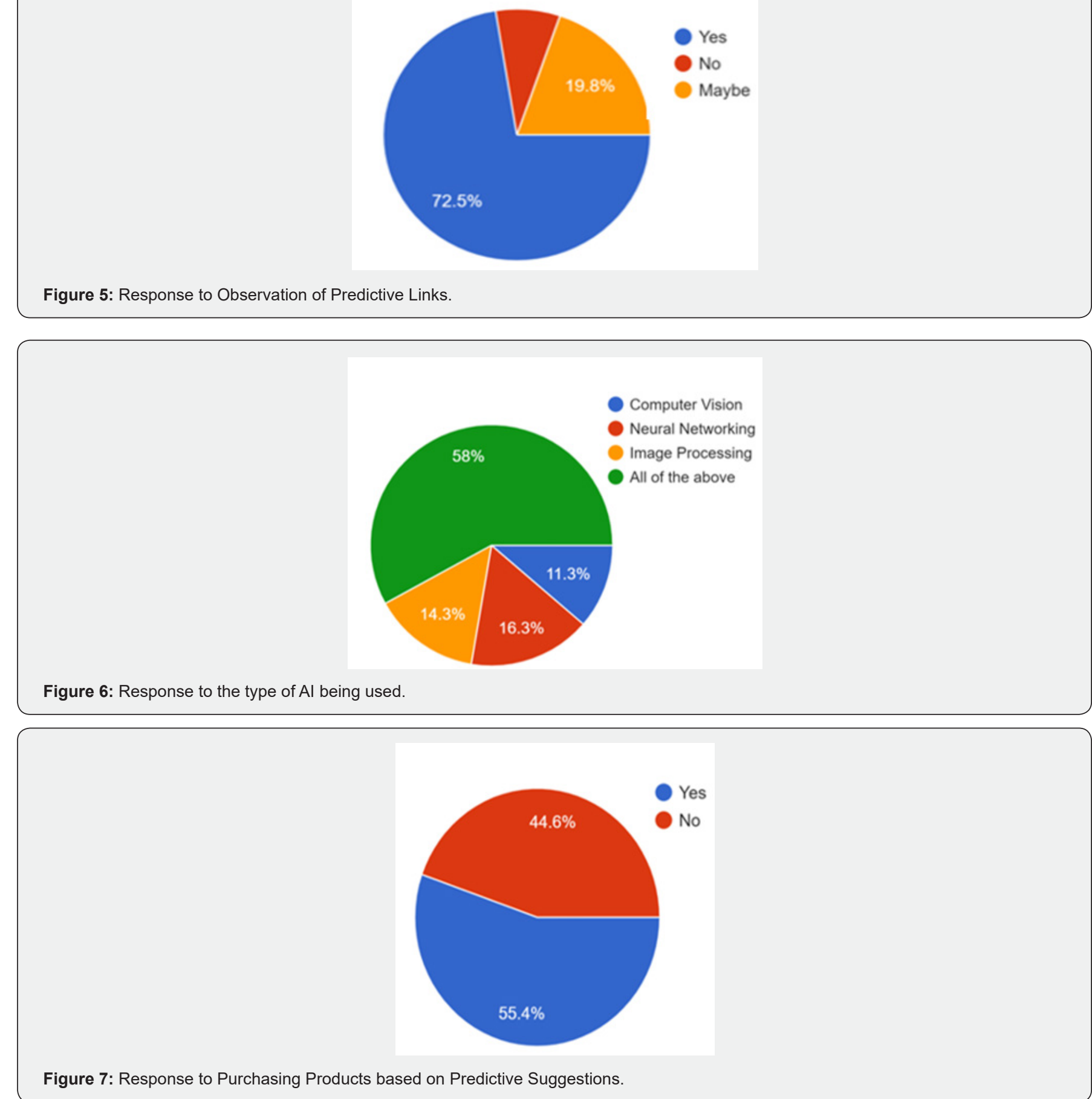

Image searching, another AI tool is present on various online apps and websites. Respondents were asked how often they have tried this option available to them. 11.1\% have always opted for Image searching while $17.4 \%$ have never tried this out. This shows the hesitance towards accepting technological upgrades generated for the ease of use of a customer (Figure 8). Voice search is another AI tool similar to Image searching that when asked about customers have faced a hesitation to use it. $50 \%$ of people were aware about the option available but for some reason abstained from using it. 37.1\% have never heard or used it. Only $12.9 \%$ were aware about the tool who were also not hesitant to use it (Figure 9). 


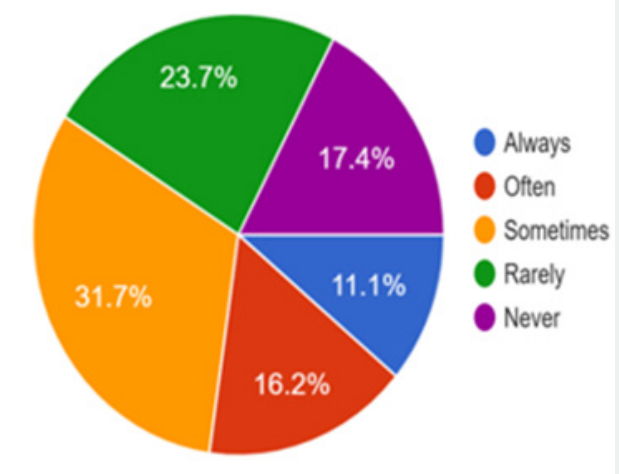

Figure 8: Frequency of the use of Image searching.

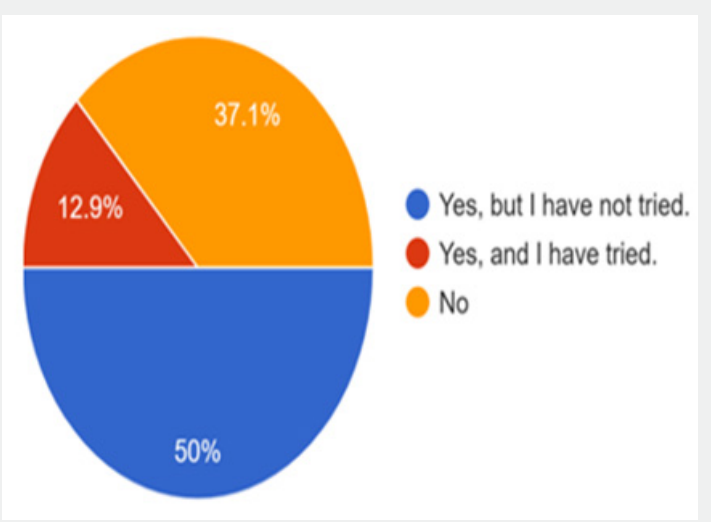

Figure 9: Awareness of Voice Search.

The survey also asked the respondents to choose the online assistance they want and need the most. The response to this question would give us valuable feedback which could be solved with the help of AI tools incorporated to satisfy the comfort of the customer. 55.7\% people opted for services regarding Inquiries of
Return and Exchange, 51.8\% wanted a satisfied buying experience, $50.6 \%$ wanted Notifications and alerts regarding availability of new stock or stocks now in supply, 38.3\% of them wanted Predictive Suggestions and $30.2 \%$ wanted services that would improve online interactions via Chatbots (Figure 10).

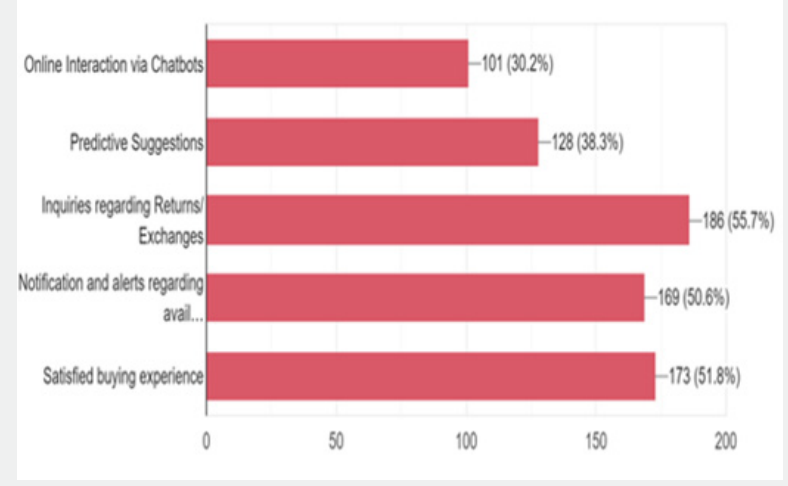

Figure 10: Type of Assistance Expected by Respondents. 


\section{Findings}

From the data analysis of the survey conducted, the results obtained are:

i. It was found that more than half of the sample have observed predictive suggestion icons and have been influenced to buy a product based on predictive suggestions.

ii. It was observed that Image searching which is the most powerful and visible AI tool on E commerce retail websites was tried by very few people.

iii. It was found that most of the people despite of being aware about the existence of Voice Powered search have never tried it.

iv. Personalized suggestions and trend forecasting have been the parameters customers are highly dissatisfied with. Inquiries regarding returns and exchange has been the most desired assistance that could mean that people are facing issues and lack of assistance in this aspect.

v. It was also identified that customers have not experienced $\mathrm{AI}$ in every E-Commerce websites. It was found that Amazon had the most votes. But some people also opted for apps like Tata Cliq and Jabong where AI is not introduced yet. This shows the unawareness amidst our respondents regarding the concept of AI.

vi. From the test it was concluded that customers' experience is negatively related to existing E-Commerce websites like live chat, customer feedback and inquiries. Inquiries regarding returns and exchanges was something people found difficulty with.

vii. It was also observed that customers have varying satisfaction level towards various services provided by E-Commerce websites. Personalized suggestions and trend forecasting have been the parameters customers are highly dissatisfied with.

viii. Most of the people are identified as satisfied with the return and refund policies offered by the E-Commerce websites.

ix. It was also noticed that there is a positive relationship between the gender and the influence of pop up notifications in their buying behaviour.

\section{Conclusion}

The survey posed us with all the problems that the respondents as customers faced and our aim was to breakdown the questions and to provide them with solutions that would simplify as well as enhance their experience by supplementing other AI tools to the existing AI models. We took in suggestions and formulated hypothesis from where we were able to identify problems that ranged from customer dissatisfaction when it came to $24 / 7$ guidance, live chats, return and other inquiries and immediate attention. A clear sense of dissatisfaction was regarding personal shopping assistance. Other frequent complaints lodged in the minds of shoppers were service issues and communication gaps. E-commerce shatters all the geographical barriers and customers can shop from anywhere they want. The advent of technology has subtly hinted clues to open our doors wide open to a world that is unafraid to take a step ahead for various possibilities.

Image Searching and Voice Recognition are seen in various online stores like Myntra and Flipkart. But despite this, people have often shown hesitation to try it, failing to understand the ease of these tools that would in turn solve a lot of their issues. With fresher approaches to revamp AI tools and algorithm, it is now possible to create an online platform where people could shop without any hesitation and to use the tools that would simplify their shopping experience and therefore create a virtual world running. Introduction of Chatbots, Augmented Reality and Trend forecasting would in turn give the customer an enhanced experience enabling the joys of shopping online becoming more concrete in vision and acceptance. Bringing this upfront could be a forte as well as a major breakthrough that ultimately even has the potential to challenge offline stores.

\section{Limitation and Future Scope}

Since the survey was held during the widespread Pandemic, it was also not possible to reach that section of population who had passive internet connection. We were also unable to collect responses that had a wider age group range since the elderly were not comfortable answering online. It is difficult to know whether willing respondents are truly representative. Had it been other modes of taking the responses, it would have willingly let us examine their behavior, their answers would have been honest and to persuade them to answer would have been easier. We also lacked sufficient information to measure the degree of advancement in Research and Development in the field of Artificial Intelligence in India.

Our question still remains suspended as of why these suggestions were not implemented in the country yet. With our secondary research we were able to formulate some suggestions to enhance the limited AI tools that the customers have had to deal with for better shopping experience as well as an overall technological revamping in the world of Indian E-commerce which is at the cusp of blooming. A Chatbot in E-commerce forms an undeniable bridge to fill in the gap that a customer has always faced while trying to shop a product online. Due to lack of tactile provisions while shopping online, customers are bound to have a thousand problems that concern returns and exchanges of a product. A customer also would be dissatisfied if his queries are not met with lucrative answers. Keeping affordability in mind, Artificial Intelligence has the potential to indulge in developing algorithms to create a Personal Shopper that helps customers pick products that suit them the best according to their personal preferences. It gives them the feeling of having their own personal 
stylist. AI is able to conduct an adaptive market study for the target audience to produce the best Trend Forecast for future patterns. The modern algorithm involves updates and self-learning method to grasp and learn from the complex demand patterns. There is no E-commerce site or any app in India that has welcomed Virtual try-on so that customers could shop clothes that suit their body type. There were no enhanced developments or application of Augmented Reality combined with AI in fashion E-commerce websites or apps to help shatter the greater problems of Indian customers- the sheer inability to try on products online while sitting at home. Bringing this upfront could be a forte as well as a major breakthrough that ultimately even has the potential to challenge Brick and Mortar stores.

\section{Acknowledgement}

The authors would like to acknowledge all the personages who have helped in this endeavour for their active guidance, help, cooperation \& encouragement and to all the reviewers for their valuable comments and discerning suggestions that has led to the improvement and completion of preliminary version of this paper.

\section{Conflict of Interest}

The authors confirm that there is no known conflict of interest associated with this work.

\section{References}

1. Bhanu Prasad (2003) Intelligent Techniques for E-Commerce. Journal of Electronic Commerce Research 4(2): 65-71.
2. Scott Siders (2018) Top 18 Ecommerce Fashion Websites to Watch in 2020.

3. Kati Chitrakorn (2018) 5 technologies transforming retail in 2018.

4. Chandadevi Giri, Sheenam Jain, Xianyi Zeng, Pascal Bruniaux (2017) A detailed review of Artificial Intelligence applied in apparel and fashion industry. IEEE 7: 95376-95396.

5. Gaurav Raturi (2018) How E-Commerce companies are using AI to drive Higher Sales \& User Experience.

6. Hien Cao (2018) The growth of e-commerce and its impact on the fast fashion retailers. pp. 1-42.

7. Aathira, Menon, Shreya, Bhagat, Shakeel Iqbal (2020) The Impact of Augmented Reality in Fashion Retail Stores in India: Opportunities and Challenges. IOSR Journal of Business and Management (IOSR-JBM) 22(7): 61-67.

8. Ekaterina Novoseltseva (2018) AI in E-Commerce: Benefits, Statistics, Facts, Use Cases, and Case Studies.

9. Ayushman Baruah (2020) Artificial Intelligence at India's Top eCommerce Firms-Use Cases from Flipkart, Myntra, and Amazon India.

10. Lei Yin (2019) Fashion AI: Revamping the Fashion and E-Commerce industry through Artificial Intelligence.

11. Iflexion (2019) How AI is revamping mobile commerce.

12. Daryna P (2018) 11 superb ways AI can revamp the retail industry.

13. Magenticians (2018) AI in E-Commerce-the next step in the evolution of online business.

14. E-tailers focusing on AI, virtual reality to cut logistics cost and fraudulent orders.

15. Katrine Spirina (2019) Top 12 AI trends transforming AI and online retail in 2019. InData labs.

\section{Your next submission with Juniper Publishers} will reach you the below assets

- Quality Editorial service

- Swift Peer Review

- Reprints availability

- E-prints Service

- Manuscript Podcast for convenient understanding

- Global attainment for your research

- Manuscript accessibility in different formats ( Pdf, E-pub, Full Text, Audio)

- Unceasing customer service

Track the below URL for one-step submission https://juniperpublishers.com/online-submission.php 